\title{
Social condition affects hormone secretion and exploratory behavior in rats
}

\section{G. Genaro, W.R. Schmidek and C.R. Franci}

Departamento de Fisiologia, Faculdade de Medicina de Ribeirão Preto, Universidade de São Paulo, Ribeirão Preto, SP, Brasil

\section{Correspondence \\ G. Genaro \\ Departamento de Fisiologia \\ FMRP, USP \\ Av. Bandeirantes, 3900 \\ 14049-900 Ribeirão Preto, SP \\ Brasil \\ Fax: +55-16-633-0017 \\ E-mail: ggenaro@rfi.fmrp.usp.br or \\ gelsongenaro@hotmail.com \\ Research supported by CNPq \\ (No. 142395/93-5) and FAPESP. \\ This work was presented at the XXVII International Ethological Conference, Tubingen, Germany, \\ August 22-29, 2001, and reported \\ in abstract form (Advances in \\ Ethology, 36: 162)}

Received March 14, 2003

Accepted February 3, 2004

\section{Abstract}

Studies of behavior, endocrinology and physiology have described experiments in which animals housed in groups or in isolation were normally tested individually. The isolation of the animal from its group for testing is perhaps the most common situation used today in experimental procedures, i.e., there is no consideration of the acute stress which occurs when the animal is submitted to a situation different from that it is normally accustomed to, i.e., group living. In the present study, we used 90 male 120-day-old rats (Rattus norvegicus) divided into 5 groups of 18 animals, which were housed 3 per cage, in a total of 6 cages. The animals were tested individually or with their groups for exploratory behavior. Hormones were determined by radioimmunoassay using specific kits. The results showed statistically significant differences between testing conditions in terms of behavior and of adrenocorticotrophic hormone (ACTH: from $116.8 \pm 15.27$ to $88.77 \pm 18.74$ when in group and to $159.6 \pm 11.53 \mathrm{pg} / \mathrm{ml}$ when isolated), corticosterone (from $561.01 \pm 77.04$ to $1036.47 \pm 79.81$ when in group and to $784.71 \pm 55.88 \mathrm{ng} / \mathrm{ml}$ when isolated), luteinizing hormone (from $0.84 \pm 0.09$ to $0.58 \pm 0.05$ when in group and to 0.52 $\pm 0.06 \mathrm{ng} / \mathrm{ml}$ when isolated) and prolactin (from $5.18 \pm 0.33$ to $9.37 \pm$ 0.96 when in group and to $10.18 \pm 1.23 \mathrm{ng} / \mathrm{ml}$ when isolated) secretion, but not in terms of follicle-stimulating hormone or testosterone secretion. The most important feature observed was that in each cage there was one animal with higher ACTH levels than the other two; furthermore, the exploratory behavior of this animal was different, indicating the occurrence of almost constant higher vigilance in this animal (latency to leave the den in group: $99.17 \pm 34.95$ and isolated: $675.3 \pm 145.3 \mathrm{~s}$ ). The data indicate that in each group there is an animal in a peculiar situation and its behavior can be detected by ACTH determination in addition to behavioral performance.

\section{Introduction}

The social behavioral patterns of a species are usually complex and of great importance to survival. Most of these behaviors
Key words

- Isolation

- Group

- Stress

- Reproduction

- ACTH

- Luteinizing hormone

- Corticosterone

- Prolactin 
spect, are the studies of Allee (1-3), since he was a pioneer researcher in the systematic study of this subject.

Group living can maximize the acquisition of food and reduce the possibility that any single individual may be preyed upon $(4,5)$. Various parameters have been used to analyze the relationships between animal raised in isolation or in social groups, such as exploratory activity, social interactions, locomotor activity and reactivity, defecation score, vigilance behavior, hormones, blood cells, vocalizing, and others. Several factors influence the exploratory activity of animals. In addition, age, genetic predisposition and even sex exert their effects (6-9). An important consideration concerning animals kept in groups is that social interactions may result in increased interest in enriched environments due to the social facilitation promoted by the group (9). Another important aspect is that animals showing a higher success rate in response to challenges in these evaluations may yield results that interfere with those of other animals (10). Thus, the study of sociability in exploratory evaluations should be undertaken with caution. In addition, the meaning of the physiological and behavioral data obtained is still controversial (11), with conflicting results having been reported in the literature. Some investigators $(12,13)$ have reported that isolated rats are more active or reactive in open-field tests, while others have reported that isolated rats show reduced spontaneous activity $(14,15)$. However, most of these tests have been carried out on animals isolated from their original groups, both when they were raised in groups and isolated. In any case, in the standard situation, at the time of the test the animal is isolated from its group and its behavioral and hormonal variations are considered to be typical control situations, i.e., an animal evaluated when separated from its group will provide physiological and behavioral measurements that are acutely affected by the condition of isolation during the test.
Thus, the information obtained in this way is considered to be a control and will be compared to any other situation in behavioral, physiological or pharmacological studies, etc. An important parameter used to compare the traditional situation is the variation in hormone secretion $(16,17)$ with particular emphasis on hormones of the hypothalamuspituitary-adrenal (HPA) axis such as corticotropin-releasing hormone, adrenocorticotrophic hormone (ACTH) and corticosterone (CT). However, other hormones could be used as markers of the stress condition to which an animal may be submitted, among them prolactin (Prl). This hormone also acts on the control of reproductive functions and behaviors. Therefore, it may be a marker of interactions between stress and reproductive changes.

The involvement of hormones of the reproductive axis (luteinizing hormone - LH, follicle-stimulating hormone - FSH, and testosterone in males) in stress situations is well known, with the occurrence of both excitatory and inhibitory actions (18).

As pointed out by Misslin et al. (19) and Marchlewska-Koj (20), behavioral and/or social changes lead to hormonal alterations and vice versa, and the situation of acute isolation of an animal from its group culminates in differentiated exploratory performances (14).

The proposal of the present study was to relate behavioral alterations to possible hormonal alterations promoted by the acute stress situation caused by the isolation of an animal from its group. To investigate the potential variation of the main hormones of the reproductive and stress axis between rats tested individually and in group, we tested the animals in a particular environment in which the animal had the option to leave the den by itself $(21,22)$. Since exploratory behavior is considered to be a form of spontaneous uncoerced behavior $(23,24)$, it represents the most suitable parameter for use in this type of study. Thus, the objective of the 
present investigation was to determine the differences in hormonal secretion and behavior between animals submitted to a stress situation (separation from their original group) and to a control situation (exploration together with the original group).

\section{Material and Methods}

\section{Animals}

We used 90 young adult male hooded Long Evans (Rattus norvegicus) rats from 30 females assigned to five different experimental conditions or 18 rats per experimental condition. After weaning, only male pups from litters of both sexes were selected at random and kept in groups of three males, with the group including no siblings. Each group was housed in a $31 \times 46 \times 17 \mathrm{~cm}$ wire mesh covered plastic cage lined with wood chip bedding. Food and water were available ad libitum and the light:dark cycle was 12:12 $\mathrm{h}$, with lights on at 6:00 am. The highest possible standards for the humane treatment of animals were used, based on the National Institutes of Health Guide for the Care and use of Laboratory Animals.

\section{Apparatus for the behavioral test}

The animals were tested in a previously described apparatus (22). Briefly, the apparatus consisted of a den compartment, i.e., a plastic cage measuring $30 \times 45 \times 16 \mathrm{~cm}$ for the group tests or $18 \times 27 \times 14 \mathrm{~cm}$ for the individual tests. This compartment is connected through a tunnel (a 7.6- $\mathrm{cm}$ diameter and $10-\mathrm{cm}$ long rigid plastic tube which could be maintained open or closed) to a complex environment consisting of five interconnected chambers. Each chamber is composed of two light blue-painted wooden compartments $(20 \times 20 \times 25 \mathrm{~cm})$ separated by a water tank $(20 \times 20 \times 10 \mathrm{~cm})$ and connected by runways of different widths. After each test the floor and walls of the system were cleaned with a cloth moistened with water, and then dried. In addition to the normal illumination of the room (six $40-\mathrm{W}$ fluorescent lamps in a $20-\mathrm{m}^{2}$ room) a $100 \mathrm{~W}$ incandescent bulb was placed $1 \mathrm{~m}$ above the last chamber of the system.

\section{Procedure}

At 113 days of age all animals were placed in contact with the system (as a group, and as a single habituation trial) for $15 \mathrm{~min}$ without behavioral recording. At 120 days of age, each animal was tested individually or together with its home group. Eighteen animals ( 6 cages of 3 animals each) was the number for each experimental category, i.e., groups I to $\mathrm{V}$. The tests were performed between 13:10 and 15:40 h, and the order of testing (individual or collective) was random. The animal or group of animals was allowed to adapt to the den compartment for a period of $30 \mathrm{~min}$ prior to the test, as previously described (21). The actual test started with the opening of the tunnel and lasted 15 min during which the behaviors of the animals were recorded on video tape and then fed to a computer for analysis. The three animals of each cage were marked with distinctive color marks on their fur 5 days before the tests. The animals were killed by decapitation and trunk blood was collected immediately after each experimental situation, as follows: group I, control, animals removed directly from their original cage and sacrificed. Group II, animals sacrificed after $30 \mathrm{~min}$ of collective adaptation to the experimental cage. Group III, animals sacrificed after 30 min of individual adaptation to the experimental cage. Group IV, animals sacrificed after $30 \mathrm{~min}$ of collective adaptation to the experimental cage followed by 15 min for the exploratory test. Group V, animals sacrificed after $30 \mathrm{~min}$ of individual adaptation to the experimental cage followed by $15 \mathrm{~min}$ for the exploratory test.

Previous analysis showed that animals 
tested independently of adaptation condition (groups IV and V) did present two different plasma ACTH profiles as well as different behavioral performances, i.e., one animal in each box showed higher plasma ACTH levels than its partners. Then, we divided the animals into two subgroups which we called "stressed" (S, showing higher plasma ACTH levels) and "partners" (P).

\section{Hormone measurements}

Blood samples were centrifuged at 2000 $g$ at $4^{\circ} \mathrm{C}$ and plasma was separated and frozen at $-20^{\circ} \mathrm{C}$ until the time for the hormone measurement. Plasma CT, testosterone, Prl, $\mathrm{ACTH}, \mathrm{FSH}$, and LH were determined by radioimmunoassay (RIA) $(25,26)$ using specific kits provided by the National Institute of Diabetes, Digestive and Kidney Diseases (NIDDK/NIH-USA). All results are reported

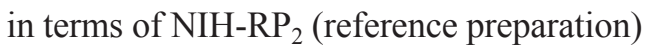
standards. The lower detection limits were $0.04 \mathrm{ng} / \mathrm{ml}$ for LH, $0.19 \mathrm{ng} / \mathrm{ml}$ for FSH and $0.19 \mathrm{ng} / \mathrm{ml}$ for Prl. In order to avoid interassay variation, all samples were measured in the same RIA at the same time. The intraassay coefficients of variation were 4, 3 and $4 \%$ for LH, FSH and Prl, respectively.

Plasma ACTH was measured by double antibody RIA (27) using iodinated ACTH$\mathrm{I}_{125}$ from NEN Life Science Products (Boston, MA, USA) and antibody and reference standards provided by the NIDDK/NIH. The lower limit of detection was $1.5 \mathrm{pg} / \mathrm{ml}$. In order to avoid inter-assay variation, all samples were measured in the same RIA at the same time. The intra-assay coefficient of variation was $7.8 \%$.

Testosterone was determined by RIA (28) using ${ }^{3} \mathrm{H}$-testosterone from NEN Life Science Products. The specific antibody was provided by Dr. J. Antunes-Rodrigues (Universidade de São Paulo, Ribeirão Preto, SP, Brazil). The lower limit of detection was 1.6 $\mathrm{ng} / \mathrm{ml}$. The intra-assay coefficient of variation was $5.4 \%$.
Plasma CT was measured using extraction with ethanol (29). The specific antibody was provided by Dr. J. Antunes-Rodrigues. All samples were measured in the same assay using ${ }^{3} \mathrm{H}$-corticosterone from NEN Life Science Products. The lower limit of detection was $50 \mathrm{pg} / \mathrm{ml}$. The intra-assay coefficient of variation was $5.8 \%$.

\section{Statistical analysis}

The performance (mean \pm SEM) for the animals tested individually or with their group was evaluated by "time outside the den compartment" (sum of the durations of all episodes in which the animal remained in the environment), "total traveled distance" (sum of all displacements of the animal between compartments of the system), "number of rearing episodes" (every time the animal stood up on its hindlimbs, leaning or not on the wall with its forelimbs), and "latency to leave the den". Values of each behavioral variable were compared by ANOVA, followed by the Tukey test when pertinent.

The values (means \pm SEM) of the plasma hormones (ACTH, LH, FSH, Prl, CT and testosterone) for each group and the behavioral data were analyzed statistically by oneway ANOVA followed by the Tukey test whenever appropriate, using the Prism 2.01 program, with the level of significance set at $\mathrm{P}<0.05$.

Groups IV and V were subdivided into two subgroups: stressed ( $\mathrm{S}$, the most stressed animal always having highest ACTH) and partners ( $\mathrm{P}$, the two cage mates).

\section{Results}

The animals of the "S" and "P" subgroups in each group exhibited a similar pattern for time in the environment, distance covered, latency to leave the den and rearing (Figure 1). Males housed together (group IV) spent more time out of the den compartment than males housed singly during the 
test, thus having a better opportunity to explore the environment. Their latencies to leave the den compartment were also more reduced and their rearings were more numerous. Thus, grouped animals explored the environment more, in terms of all the items studied, when compared to group V animals (animals submitted to the exploratory test separate from their group mates). Statistically significant differences $(\mathrm{P}<0.05)$ were observed between group IV/S $v s \mathrm{~V} / \mathrm{S}$ (b) and group IV/P vs V/S (d).

In each cage one animal had significantly higher circulating ACTH levels than cage mates. This difference was not observed for the other hormones tested. Figure 2 shows plasma ACTH for the "S" (the most stressed animal in the cage) and "P" (the other two partners) subgroups in each experimental group. There was a significant difference between subgroups "S" and "P" within each experimental group (I, II, III, IV and V; $\mathrm{P}<$ 0.05 ) and between group I and groups II, III, IV and V. Plasma ACTH was lower $(\mathrm{P}<$ 0.05 ) in group IV (collective test) than in group V (individual test).

Figure 2 also shows plasma Prl, $\mathrm{LH}$ and $\mathrm{CT}$ for the five groups studied. There were several differences among groups, with the hormonal responses differing between experimental situations. Plasma Prl increased during the procedure (adaptation for the first $30 \mathrm{~min}$ and the $15 \mathrm{~min}$ of the test), while $\mathrm{LH}$ showed the opposite response. Finally, CT showed a significant rapid increase followed by a decrease. No difference in plasma FSH or testosterone was observed between groups (data not shown).

\section{Discussion}

The most important difference of the present experiment compared to others in the current literature is that the animals were tested at the same time with their group or isolated. We observed two important results: 1) the animals showed greater exploratory behavior when tested together with their original group than in isolation, and 2) one animal in each cage was in a state of constant alert even when the group was not stressed (group I) by the experimental procedures.

The present model provides a unique opportunity to study the variation of hormone secretion and behavior in animals tested in isolation or together with their group. Analysis of Figure 1 shows the higher ex-
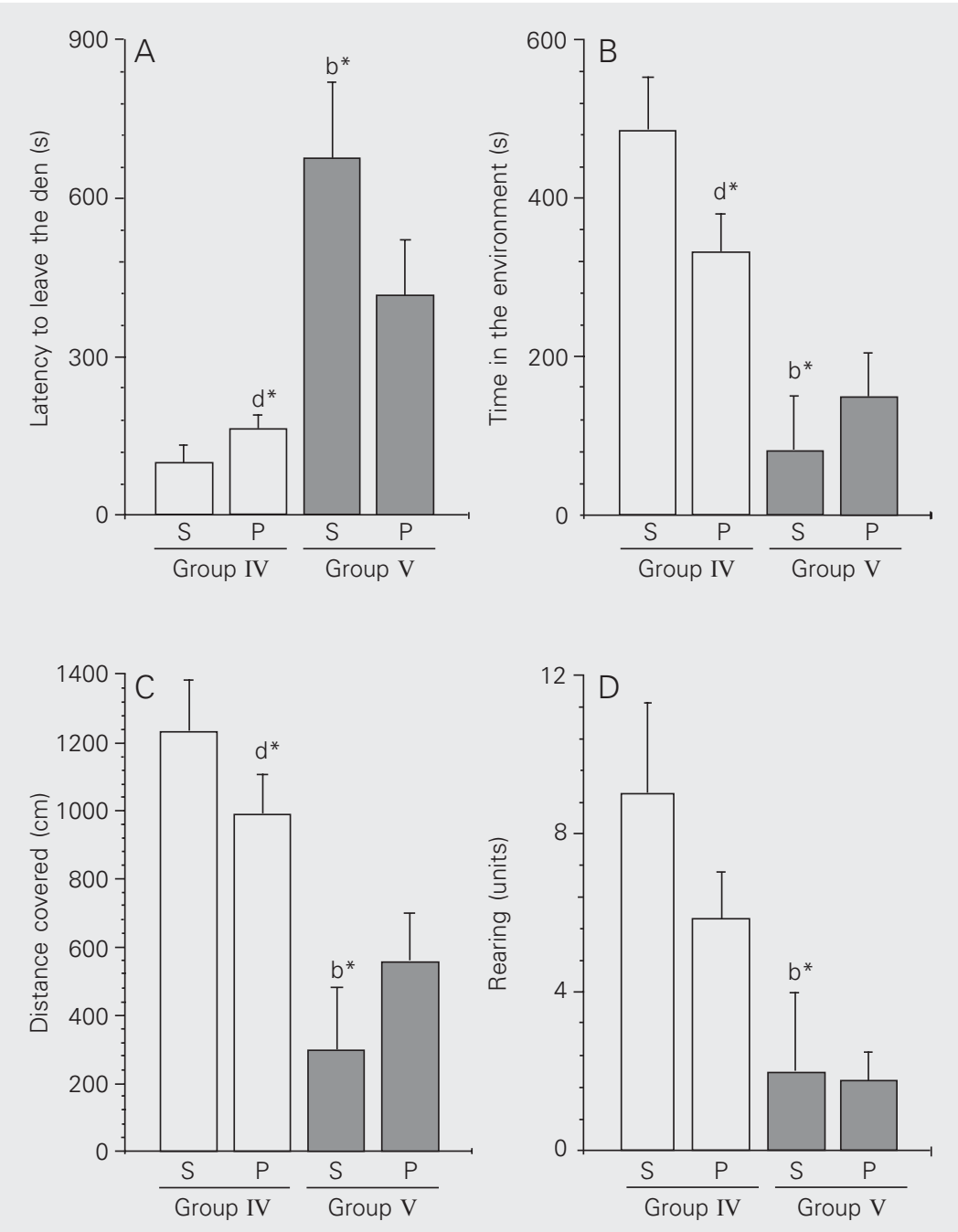

Figure 1. Behaviors studied in the exploratory tests applied to grouped (IV) or isolated (V) animals submitted to $30 \mathrm{~min}$ of adaptation to specific conditions (grouped or isolated) and then to $15 \mathrm{~min}$ of effective exploratory test. $A$, Latency to leave the den; $B$, time in the environment; $C$, distance covered; $D$, rearing. Both groups (collective - IV and isolated - V) were divided into two subgroups ("S" - most stressed animal in the cage, and "P" - the other two animals in the cage). Significant differences were observed between group IV/S and V/S (b) and group IV/P and V/S (d) $\left({ }^{*} P<0.05\right.$, ANOVA). The number of animals was 6 for subgroup " $\mathrm{S}$ " and 12 for subgroup " $\mathrm{P}$ ", both for groups IV and V. 

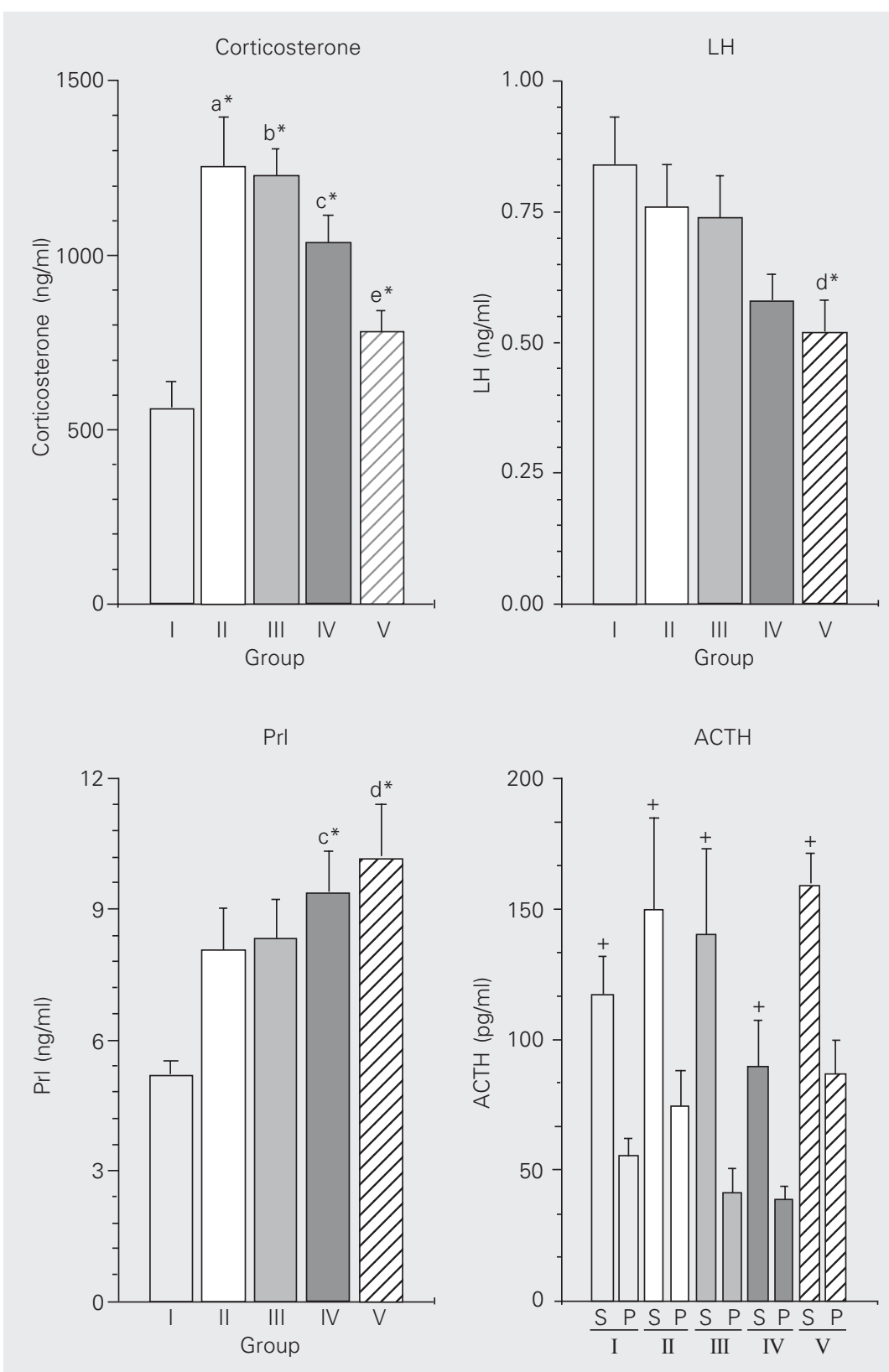

Figure 2. Plasma hormone levels: prolactin (Prl), luteinizing hormone (LH), corticosterone (CT), and adrenocorticotropic hormone (ACTH) in the following groups: I, no manipulation; II, 30 min for adaptation of the animals of the same original group to a new cage; III, $30 \mathrm{~min}$ for adaptation of the animal isolated from the group and placed in a new cage; IV, 30 min for adaptation and $15 \mathrm{~min}$ for the collective exploratory test; $\mathrm{V}, 30 \mathrm{~min}$ for adaptation and 15 min for the individual exploratory test. For plasma ACTH determination, the groups were divided into two subgroups: "S" (the most stressed animal in the cage) and " $P$ " (the other two partners). ${ }^{*} \mathrm{P}<0.05$, significant differences were observed between a) group I vs II, b) group I vs III, c) group I vs IV, d) group I vs V, e) group III vs V (one-way ANOVA). $+\mathrm{P}<0.05$, significant differences were observed between subgroups " $S$ " and " $P$ " within each experimental group for $\mathrm{ACTH}$. The number of animals was 17 for the determination of $\mathrm{CT}$, 17-18 for LH, and 15-17 for Prl. For ACTH, the number of animals was 6/12 for subgroups "S" and "P" in groups I and II, 6/9 for group III, 6/10 for group IV, and 6/11 for group V. ploratory behavior of grouped animals in terms of the four items studied, i.e., distance covered, rearing, time in the environment, as well as latency to leave the den. This situation elicited an ideal performance (a situation nearest the natural behavior of this species) by all members of the group, even the most alert ("S") one, whereas an animal tested separately became more alert and explored less.

Social interactions are complex phenomena, substantially related to endocrine responses (20). Acute disturbances of standard conditions are quickly reflected in plasma hormone concentrations. In other words, hormone secretion rapidly changes in animals submitted to new maintenance conditions (19), reflecting social or behavioral alterations. For this reason, under free living conditions the animals perform their behaviors at the "periphery or in the central area" of their group both as a function of their behaviors and hierarchy and as a function of their hormonal profiles (intimately related factors) and hormonal and behavioral evaluations complement each other in an important manner.

Most of the studies in this area approach the alteration of the HPA axis as a function of social situation, with special emphasis on litter-mother relationships, and have been mainly conducted on primates (16), monogamous species such as prairie voles (Microtus ochrogaster) (30), or species kept in pairs, such as hamsters (Phodopus sungorus) (31). However, other types of social relationships among adult animals eventually can affect the HPA axis (32). Relationships among adult animals, especially rats, represent the most usual situation in scientific research, although at present the number of publications in this area is small. The understanding of these endocrine and social parameters in adult rats is of paramount importance since this species is used in several studies of behavior and the animals are frequently isolated for analysis. 
Work with hamsters (31) has shown that plasma cortisol increases $(\mathrm{P}<0.05)$ in isolated animals, whereas testosterone is unaffected. Other studies have shown hormonal variations in animals submitted to different maintenance conditions $(13,16)$. However, these studies always focus on support conditions, without considering an acute situation such as exploratory tests.

Rats form social groups gradually during development, with social structure being usually complete at about 150 days of age (33). Rats raised in isolation have been reported to have higher basal CT levels and lower resistance to restraint stress than rats raised in small groups (34). It is possible that even the acute isolation such as that used in our experiment may have an alerting effect leading to a reduction in exploratory motivation. Isolated animals when exploring a new environment are thus more prone to alert reactions (35) and tend to have reduced exploratory behavior.

Work with capybaras (Hydrochaeris hydrochaeris) (5) has demonstrated that not all individuals of a social species benefit equally from the advantage of living in groups. Among these animals living in large groups, females show reduced vigilance, whereas subordinate males living under more isolated conditions spend more time in vigilance.

In the present study, significant physiological differences in hormone release were observed in the alert "S" animal (Figure 2), especially in terms of ACTH concentration, which was determined in animals sacrificed immediately after the test. Changes in the release of other hormones, with lower fluctuations, probably also occurred after a longer period of time. Plasma CT (Figure 2) also showed differences, probably as a consequence of general procedures, and not necessarily due to isolation since the increase in this hormone did not depend on the social or isolated situation.

The present results show that plasma Prl increased while plasma LH decreased during stress, with the highest plasma Prl values and the lowest plasma LH values being detected in group V. It has been shown that stress stimulates Prl release (36-38) and inhibits LH release (39). Thus, the present results agree with previous reports and describe other markers (like isolation of the original group) of the stress condition in animals of group $\mathrm{V}$.

Taken together, our results indicate the importance of the association of endocrinologic and behavioral studies and emphasize the necessity for a collective approach to social species such as the rat, as well as the importance of the social environment for the motivational regulation of behavior in this species.

\section{Acknowledgments}

We thank Professor José Antunes-Rodrigues (FMRP-USP) for his kind and generous gift of antibodies. Mr. Humberto Giusti and Ms. Sônia A. Zanon provided excellent technical assistance.

\section{References}

1. Allee WC (1931). Animal Aggregations. Chicago University Press, Chicago, IL, USA.

2. Allee WC (1942). Group organization among vertebrates. Science, 95: 289-293

3. Allee WC (1958). The Social Life of Animals. Beacon, Boston, MA, USA.

4. McNamara JM \& Houston A (1992). Evolutionarily stable levels of vigilance as a function of group size. Animal Behavior, 43: 641-658.

5. Yáber MC \& Herrera EA (1994). Vigilance, group size and social status in capybaras. Animal Behavior, 48: 1301-1307.

6. Welker MI (1957). "Free" versus "forced" exploration of a novel situation by rats. Psychology Reports, 3: 95-108.

7. Renner MJ \& Rosenzweig MR (1986). Object interaction in juvenile rats (Rattus norvegicus): Effects of different experiential histories. 
Journal of Comparative Psychology, 100: 229-236.

8. Renner MJ \& Seltzer CP (1991). Molar characteristics of exploratory and investigatory behavior in the rat (Rattus norvegicus). Journal of Comparative Psychology, 105: 326-339.

9. Renner MJ, Bennett AJ \& White JC (1992). Age and sex as factors influencing spontaneous exploration and object investigation by pre adult rats (Rattus norvegicus). Journal of Comparative Psychology, 106: 217-227.

10. Fragaszy DM \& Adams-Curtis LE (1991). Environmental challenges in groups of capuchins. In: Box HO (Editor), Primate Responses to Environmental Change. Chapman \& Hall, London, England, 239264.

11. Niesink RJM \& Van Ree JM (1982). Short term isolation increases social interactions of male rats: a parametric analysis. Physiology and Behavior, 29: 819-825.

12. Syme AL (1973). Social isolation at weaning: some effects on two measures of activity. Animal Learning and Behavior, 1: 161-163.

13. Gentsch C, Lichtsteiner M \& Feer $H$ (1981). Individual housing in rats causes divergent changes in spontaneous and reactive activity. Experientia, 37: 61-62.

14. Genaro G \& Schmidek WR (1999). Exploratory behavior of rats in isolation and in group. Revista de Etologia, 1: 99-104.

15. Gentsch C, Lichtsteiner M \& Feer H (1981). Locomotor activity, defecation score and corticosterone level during an open field exposure: a comparison among individually and group-housed rats, and genetically selected rat lines. Physiology and Behavior, 27: 183-186.

16. Hennessy MB (1997). Hypothalamic-pituitary-adrenal responses to brief social separation. Neuroscience and Biobehavioral Reviews, 21: 11-29

17. Wingfield JC, Jacobs J \& Hillgarth N (1997). Ecological constraints and the evolution of hormone-behavior interrelationships. Annals of the New York Academy of Sciences, 807: 22-41.

18. Welsh TH \& Johnson BH (1981). Stress-induced alterations in secretion of corticosteroids, progesterone, $\mathrm{LH}$ and testosterone in bulls. Endocrinology, 109: 185-190.

19. Misslin R, Herzog F, Koch B \& Ropartz P (1982). Effects of isolation, handling and novelty on the pituitary-adrenal response in the mouse. Psychoneuroendocrinology, 7: 217-221.

20. Marchlewska-Koj A (1997). Sociogenic stress and rodent reproduction. Neuroscience and Biobehavioral Reviews, 21: 699-703.

21. Genaro G \& Schmidek WR (2000). Exploratory activity of rats in three different environment. Ethology, 106: 849-859.

22. Genaro G \& Schmidek WR (2002). The influence of handling and isolation post weaning on open field, exploratory and maternal behavior of female rats. Physiology and Behavior, 75: 681-688.

23. Renner MJ (1990). Neglected aspects of exploratory and investigator behavior. Psychology, 18: 16-22.

24. Poucet B \& Herrmann T (2001). Exploratory patterns of rats on a complex maze provide evidence for topological coding. Behavioural Processes, 53: 155-162.
25. Niswender GD, Midgley Jr AR, Monroe SE \& Reichert Jr LE (1968). Radioimmunoassay for rat luteinizing hormone with antibovine $\mathrm{LH}$ serum and ovine LH ${ }^{131} \mathrm{I}$. Proceedings of the Society for Experimental Biology and Medicine, 128: 807-811.

26. Niswender GD, Chen CL, Midgley Jr AR, Meites J \& Ellis E (1969). Radioimmunoassay for rat prolactin. Proceedings of the Society for Experimental Biology and Medicine, 130: 793-797.

27. Nicholson WE, Davis DR, Sherrell BJ \& Orth DN (1984). Rapid radioimmunoassay of corticotropin in unextracted human plasma. Clinical Chemistry, 30: 259-265.

28. Moreno MC, Wickings EJ \& Nieschla G (1980). Methodology of radioimmunoassay for testosterone. In: Gupta D (Editor), Radioimmunoassay of Steroid Hormones. Verlag Cheme, New York.

29. Vecsei P (1979). Glucocorticoids: cortisol, corticosterone and compounds. In: Jaffe M (Editor), Methods of Hormone Radioimmunoassay. Academic Press, San Diego, CA, USA, 767-792.

30. Devries AC, Taymaus SE \& Carter CS (1997). Social modulation of corticosteroid response in male prairie voles. Annals of the New York Academy of Sciences, 807: 494-497.

31. Castro WRL \& Matt KS (1997). Neuroendocrine correlates of separation stress in the Siberian dwarf hamster (Phodopus sungorus). Physiology and Behavior, 61: 477-484.

32. Sachser N, Dürschlag M \& Hirzel D (1998). Social relationships and the management of stress. Psychoneuroendocrinology, 23: 891904.

33. Adams N \& Boice R (1989). Development of dominance in domesticated rats in laboratory and seminatural environments. Behavioural Processes, 19: 127-142.

34. Gamallo A, Vilanua A, Trancho G \& Fraile A (1986). Stress adaptation and adrenal activity in isolated and crowded rats. Physiology and Behavior, 36: 217-221.

35. Roberts $G$ (1995). A real-time response of vigilance behavior to changes in group size. Animal Behaviour, 50: 1371-1374.

36. Noel GL, Suh HK, Stone JG \& Frantz AG (1972). Human prolactin and growth hormone release during surgery and other conditions of stress. Journal of Clinical Endocrinology and Metabolism, 35: 840851.

37. Portiroli AE, Baro G \& Stella L (1982). Effects of naloxone on prolactin, luteinizing hormone, and cortisol response to surgical stress in humans. Journal of Clinical Endocrinology and Metabolism, 55: 378380.

38. Franci CR, Anselmo-Franci JA \& McCann SM (1992). The role of atrial natriuretic peptide in resting and stress-induced release of corticotropin, prolactin, growth hormone and thyroid-stimulating hormone. Proceedings of the National Academy of Sciences, USA, 89: 11391-11395

39. Blake CA (1975). Effects of stress on pulsatile luteinizing hormone release in ovariectomized rats. Proceedings of the Society for Experimental Biology and Medicine, 148: 813-815. 